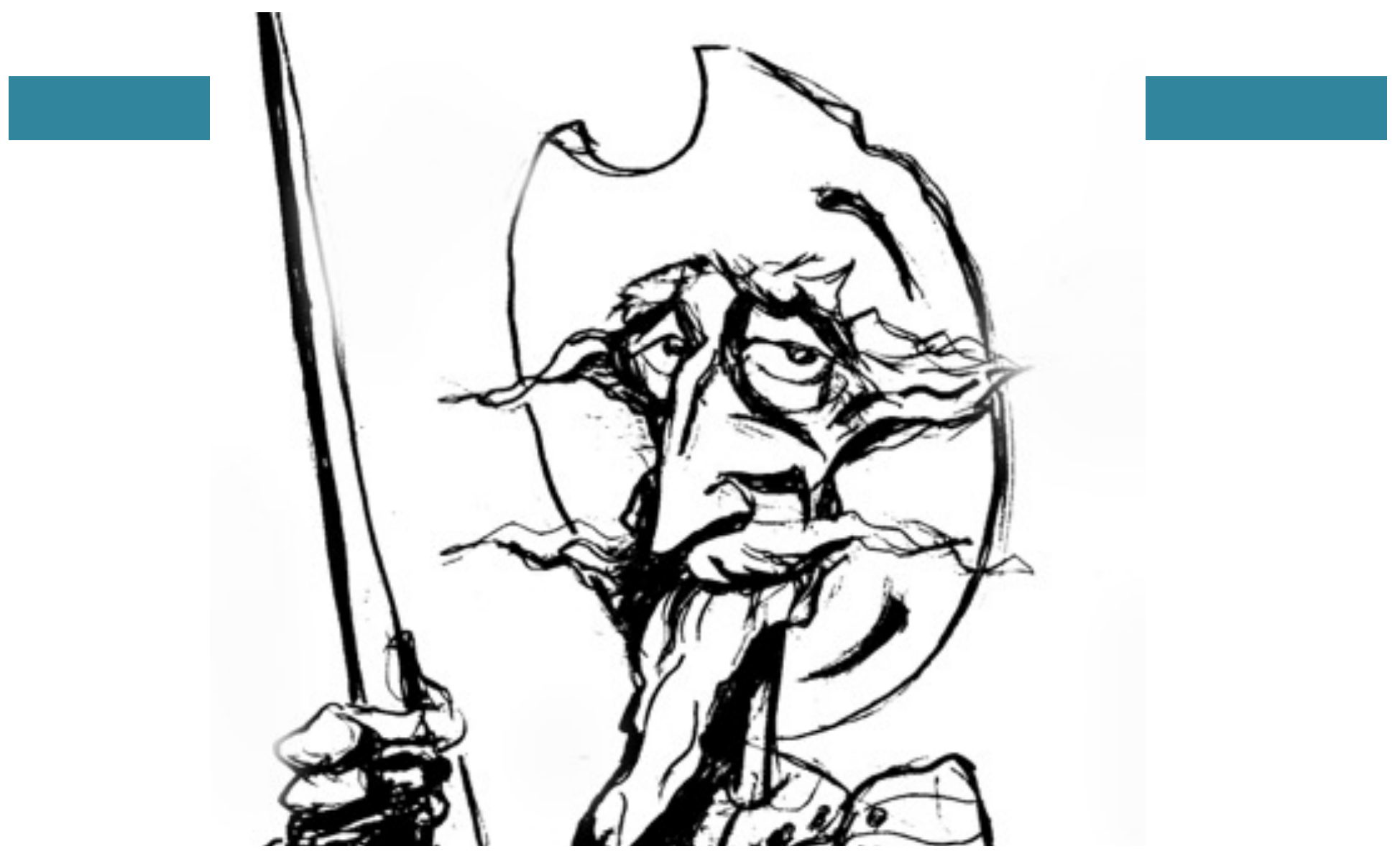

De la biblioteca a la cocina y de los yerbatales al puerto preciso.

Juan Carlos Garavaglia, trayectorias subjetivas de una presencia que no cesa.

[Darío G. Barriera] 


\section{De la biblioteca a la cocina y de los yerbatales al puerto preciso. Juan Carlos Garavaglia, trayectorias subjetivas de una presencia que no cesa*}

\section{From the library to the kitchen and from the yerbatales to the precise port. Juan Carlos Garavaglia, subjective trajectories of a permanent presence}

DARÍO G. BARRIERA

\section{Resumen}

El texto, surgido de una exposición en el homenaje ofrecido a Juan Carlos Garavaglia en la Universidad Nacional del Litoral el 18 de mayo de 2017, enlaza trayectorias interpersonales con el propósito de mostrar el lugar que ocupa en su obra la ciudad de Santa Fe, ciudad que lo acogió como investigador durante los últimos años de su vida.

\section{Palabras clave}

Juan Carlos Garavaglia - Santa Fe - Mercado Interno - Economía Colonial - Espacio Económico

\begin{abstract}
The text, emerged from a tribute offered to Juan Carlos Garavaglia at the National University of the Litoral on May 18, 2017, connects interpersonal trajectories and shows the place occupied by the colonial city of Santa Fe in his work.
\end{abstract}

\section{Key words}

Juan Carlos Garavaglia - Santa Fe - Internal Market - Colonial Economy - Economic Space

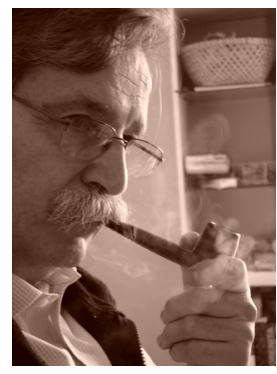

Recibido con pedido de publicación el 25 de julio de 2017

Aceptado para su publicación el 10 de septiembre de 2017

Versión definitiva recibida el 28 de septiembre de 2017

Darío Barriera, Centro de Historia Social de la Justicia y el Gobierno, Universidad Nacional de Rosario / Investigaciones Socio-Históricas Regionales, Consejo Nacional de Investigaciones Científicas y Técnicas, Argentina; e-mail: dgbarriera@yahoo.com.ar

\footnotetext{
* La primera versión de este texto fue parte de lo ofrecido durante el panel "Juan Carlos Garavaglia: homenaje al Historiador y Maestro", que compartimos con Raúl Fradkin el 18 de mayo de 2017, a modo de apertura del VII Congreso Regional de Historia e Historiografía, Facultad de Humanidades y Ciencias, Universidad Nacional del Litoral. Agradezco muchísimo a los organizadores de ese Congreso la oportunidad de haber podido compartir oral y públicamente una parte de estas palabras.
}

Esta obra se publica bajo licencia Creative Commons. Atribución-NoComercial-CompartirIgual Internacional

Barriera, Darío G. "De la biblioteca a la cocina y de los yerbatales al puerto preciso. Juan Carlos Garavaglia, trayectorias subjetivas de una presencia que no cesa", Prohistoria, Año XX, núm. 28, Homenaje a Juan Carlos Garavaglia, dic. 2017, pp. 289-299. 
Prohistoria, Año XX, núm. 28, dic. 2017, ISSN 1851-9504 
"En Beethoven no hay fragmentos de relleno, sin interés, él se expresa siempre con pasión,

con furia, con tristeza, con alegría, con sufrimiento, nunca murmura..." ${ }^{1}$

Sé que en esta ocasión, que considero un regalo, se me ha brindado el privilegio de hacer uso de la palabra para homenajear a Juan Carlos Garavaglia no sólo porque los organizadores de este congreso confían en que pudiera haber leído una parte de su trabajo, sino porque lo conocí, porque lo quise y lo quiero mucho, y porque él tuvo la gentileza de distinguirme con su amistad. Por eso siento el dulce deber -que cabalga entre la necesidad y la obligación- de explicitar esa primera trayectoria trazada metafóricamente, entre bibliotecas y cocinas.

Es que como muchas veces pasa, más terrenal que bíblicamente, en el principio fue apenas un nombre. Un nombre estampado en copias que recuerdo opacas de nacimiento, grisáceas, integrando un cuadernillo de materiales de estudio tamaño oficio, abrochado, impreso a bajo costo por el centro de estudiantes de nuestra Facultad. ${ }^{2}$ Era mayo de 1986, y el bloque de papeles, cuya talla escapaba a cualquier carpeta, nos reclamaba, amenazante, para comenzar a dar cuentas en los "trabajos prácticos" del cursado de una asignatura, la de Historia de América Colonial. El fardo contenía, entre otras cosas evidentemente olvidables, una selección del célebre Modos de producción en América Latina, más conocido como el PyP $40 .^{3}$ La curiosidad y en definitiva, un estimulado interés, hicieron que la copia dejara enseguida lugar al libro que costó 4,96 australes. Así lo testimonia todavía, en su última página, la inconfundible notación cifrada de Leopoldo Laborde, por aquél entonces dueño de la librería "Jorge Serafín" en la calle Santa Fe 2135, aquí en Rosario. Así fue que el nombre pasó de las copias a la biblioteca. ${ }^{4}$ Más adelante sobrevino la

1 BERGMAN, Ingmar Linterna mágica, Tusquets, Buenos Aires, 2015 [Estocolomo, 1987], p. 239 (son palabras que el autobiografiado pone en boca de la pianista Andrea Vogler-Corelli.

2 De la Facultad de Humanidades y Artes de la Universidad Nacional de Rosario, donde a cursaba la carrera de Historia. La cantidad de citas en este texto trata de evitar a cualquier lector prolongaciones que podría encontrar con justicia innecesarias pero las incluí pensando en los actuales estudiantes de de Historia, sobre todo en los de mi Universidad, en los ayudantes de la Cátedra de Historia de América II (Colonial), a quienes prefiero abrir ventanas a la curiosidad antes que cerrar el texto en un logos críptico que, para ellos, podría estar lleno de referencias que les son inevitablemente ajenas.

3 Se trataba de una décima edición mexicana, impresa en el DF, de uno de los Cuadernos de Pasado y Presente que se había editado en Córdoba en 1973. Los "cuadernos" fueron libros que, a partir de 1968, se publicaban como sueltos y que, en definitiva, publicados en México por Siglo XXI editores, sobrevivieron a la revista (que se editó en Córdoba entre 1963 y 1973). Sobre la serie, véase CRESPO, Horacio "En torno a Cuadernos de Pasado y Presente, 1968-1983", en HILB, Claudia -compiladora-El político y el científico. Ensayos en homenaje a Juan Carlos Portantiero. Buenos Aires, Siglo XXI/UBA, 2009. Sobre la revista, puede verse el trabajo de RUBIO, Alicia "Crisis y creación. Apuntes para una historia de la revista Pasado y presente.", Estudios, núm. 5, CEAC, Córdoba, pp. 13-20.

4 Juan Carlos Garavaglia firmaba la introducción -que, sin anestesia, en las primeras 50 palabras, explicaba la diferencia entre modo de producción y formación económico-social- y un artículo titulado "Un modo de producción subsidiario: la organización económica de las comunidades guaranizadas durante los siglos XVII-XVIII en la formación regional altoperuanarioplatense" AA. VV. Modos de producción en América Latina, Siglo XXI Editores, $10^{\mathrm{a}}$ edición, México, 1984, pp. 161-191 (la primera edición es de 1973). Este trabajo tiene una particularidad que por diversas razones nunca dejó de impactarme: las notas triplican en volumen al texto, y son un fenomenal cuaderno de bitácora de la investigación que respaldaba sus reflexiones y explican, en suma, el modo en que construía teoría. 
compra de un ejemplar de Mercado interno y economía colonial, que desvencijado- acompaña al otro y ambos me acompañan a mí, aquí, en este momento. Después vinieron más.

En algún momento pude ponerle cara al nombre. Eran tiempos sin google, andábamos por ahí sin red. Algunos privilegiados tenían teléfono y el número, en las grandes ciudades, se reducía a 5 cifras. A finales de los 1980 o comienzos de los 1990 -cuando asistí a un seminario que dictó en Rosario- lo conocí como profesor, función que formalmente cumplió para mí a partir de 1997, en la École des hautes études en sciences sociales. Los viernes dictaba un seminario en el 105 de Boulevard Raspail, donde asistí a clases suyas y de Jorge Gelman, entre otros. Para abreviar, luego devino el maestro involuntario, el miembro del tribunal que fue juez de mi tesis de doctorado, el que motu proprio se acercó para darme buenos consejos cuando supo que iría a trabajar México y más tarde, el que me propuso a que fuera su editor en un proyecto, que luego fueron dos, tres y cuatro. Desde finales de 2004, cuando sus visitas a Rosario se convirtieron en una residencia a tiempo parcial pero largo y tuvo casa también de este lado del Atlántico y del Arroyo del Medio con su compañera Elisa Caselli, compartió con nosotros muchos momentos ligados a la vida de la revista donde hoy publicamos este homenaje, y pudimos disfrutarlo en casa de Tatato Baravalle o en la mía -después, ya con Miriam Moriconi, en la nuestra-como el anfitrión, el invitado, el amigo, el dueño de un anecdotario de sobremesa desopilante, el cocinero, el buen degustador de vinos, y el que no podía evitar asomar su nariz en tu cocina o tu parrilla, sobre todo preocupado porque la carne no dejara de mugir. Sempre viva.

La segunda trayectoria, bastante más intersubjetiva que aquella, tiene que ver con el día de hoy y con la presencia de todos ustedes en este auditorio de la Universidad Nacional del Litoral que legítimamente espera alguna palabra sobre su obra o sobre un fragmento de ella. Obra enorme, inabarcable incluso en formatos más apropiados, como podría serlo el de un largo seminario. ¿Qué elegir para esta hora? ¿Cuál es el fragmento más pertinente para honrar esta mañana su memoria iluminando alguna zona de esa vasta floresta que es su obra escrita y publicada sólo como historiador? ¿Recuperar el legado de una creativa historia económica? ¿O volver sobre aquellos inspirados textos donde discutía el marxismo de los años setenta? ¿Releer esos debates a la luz de sus propios ejercicios de egohistoria? ${ }^{5} i \mathrm{O}$ mostrar la presencia, primero latente y luego preferente de lo ecológico y lo ambiental en su modo de estudiar el pasado litoraleño y pampeano ${ }^{6}$ Descarto por razones evidentes referirme a su preocupación por las clases populares -me inhibe y me releva de hacerlo la sola la presencia de Raúl Fradkin en el panel-. Y dudo nuevamente: ¿sería mi deber entonces el imposible expurgo, durante este breve encuentro, de la tremenda incidencia que tuvo su potente interpretación sobre la justicia rural rioplatense para quienes hacemos tanto historia rural como historia de la justicia? ¿O es esta una ocasión más propicia para hablar del Juan Carlos que conocí siendo su editor? ¿O de su militante posición sobre los libros en papel y las bibliotecas?

5 Me refiero, claro está, a su Una juventud en los años sesenta, Prometeo Libros, Buenos Aires, 2015, 208 pp.

6 Quien quiera hacerlo debe preparar una larga lista de artículos y, sobre todo, leer con atención Pastores y labradores de Buenos Aires. Una historia agraria de la campaña bonaerense (1700-1830), Ediciones de la Flor, Buenos Aires, 1999, 408 pp. Un interesantísimo cruce con la historia presente en la introducción al dossier "El conflicto de las papeleras entre Uruguay y Argentina" que coordinó junto a Denis Merklen (el texto se llama "Las dos márgenes de un problema", para Nuevo Mundo Mundos Nuevos [En línea], Cuestiones del tiempo presente, Puesto en línea el 21 enero 2008, DOI: 10.4000 / nuevomundo.17383 
Cuando las hojas de la margarita imaginaria se extinguían me encontré involuntariamente pensando en el río, en el omnipresente río que es todos los ríos, los ríos de sus libros y los de su vida, el Paraná y el Sena, el Areco o el Paraguay; o aquellos de la región de Puebla, que nombraba y no recuerdo. Pero para este hoy y aquí, al lado de la Setúbal y tan cerca del Salado, me decanté por apuntar el lugar que ocupa en su obra Santa Fe, la ciudad donde reside esta Universidad y el Instituto que lo acogieron como investigador durante los que no sabíamos que eran los últimos meses de su vida.

Como afirmó Jorge Gelman en la presentación que escribió para la edición que preparamos en Rosario homenajeando el $25^{\circ}$ aniversario de su aparición (2008), Mercado interno y economía colonial (subtitulado en su página de legales, tibiamente y entre paréntesis, Tres siglos de historia de la yerba mate), es un libro cuyo único defecto era la encuadernación. Alguna falla técnica, seguramente achacable a la temperatura de la goma en el momento de empastar la tapa con los interiores ya prensados, es la responsable de que aquella edición de Grijalbo fuera tan hermosa como frágil. ${ }^{7}$

Es un libro que ningún historiador debiera ignorar pero, y esta es la letra chica del pétalo decisivo que desnudó por fin la margarita, que ningún santafesino -historiador o no- debiera dejar de leer. Aunque sea por un acceso temporal de chovinismo, por puro orgullo parroquial, o, si se aviene al convite, para captar mejor que en ningún otro libro, hasta qué punto y de qué manera, su lugar, ese que le parece tan obvio y cotidiano, estaba inserto en un mundo mucho más ancho y ajeno, bullente, para el cual su ciudad y su gente fueron absolutamente centrales, indispensables.

Mercado interno... es un libro hipnótico, complejo y completo, que parece imaginado y redactado por el último Juan Carlos y no por el tesista dirigido por Ruggiero Romano. Es un libro de madurez escrito durante la juventud, una perla intensivamente cultivada por alguien que era mucho más que un aprendiz de brujo.

Desde el principio, y gracias a esa capacidad muchas veces demostrada de entrar frontalmente en tema, Garavaglia sacude nuestra modorra y nos obliga a imaginar un pasado donde lugares muy lejanos palpitan conectados por gente en movimiento. Es absurdo, nos dice, pensar que a un real de minas las mulas o el sebo lleguen desde Europa. "Es tan impensable un Potosí sin maderas, leña, paja, carbón, sebo, cueros, mulas, como sin hierro o azogue... Es asimismo difícil imaginarlo sin vacas, vino, aguardiente, coca, yerba mate, azúcar, ponchos lienzos, como sin papel, telas de Lyon, brabantes o pontivíes..." 8

Es que la mentada timidez del subtítulo estaba relacionada con una convicción profunda: en este libro, dedicado a la yerba mate, lo que realmente importa es la gente: lo que capta con firmeza su atención son las relaciones sociales. Como se encarga de aclarar enseguida, “...lo social es la trama que hace inteligible lo económico y todo intento de separar es nada más que el resultado de la incomprensión de una vieja imagen marxiana poco feliz...". ${ }^{9} \mathrm{Y}$ es en uno de los pliegues de esa discusión sobre las categorías marxianas que se encuentra

7 GARAVAGLIA, Juan Carlos Mercado interno y economía colonial, Enlace-Grijalbo, México, 1983, 508 pp. Nuestra edición, prologada por Jorge Gelman, con el mismo título, Prohistoria Ediciones, Rosario, 2008.

8 GARAVAGLIA, Juan Carlos Mercado interno..., cit., p. 19.

9 GARAVAGLIA, Juan Carlos Mercado interno..., cit., p. 22. 
ya bien explicitada en su intervención en el PyP 40 -aquella fotocopia devenida libro- donde aparece la clave que nos trae al punto. Antes de terminar aquella introducción, avisa:

"Como se sabe, en todas las formaciones coloniales, la circulación prima sobre la producción y el capital comercial existe como forma autónoma del capital. En los diversos acápites estudiaremos entonces las características peculiares de la circulación monetaria, con sus 'pesos huecos' como monedas de cuenta y sus diversos niveles sociales. [...] terminamos la exposición mostrando concretamente de qué modo mercaderes y traficantes funcionan como organizadores de la producción y como vehiculizadores del excedente colonial..."10

Y allí es donde se preanuncia el lugar que en el libro tendrá la ciudad de Santa Fe y su gente, comenzando por uno de sus hijos adoptivos dilectos.

Tratándose de la yerba mate, no es extraño que la figura de Hernandarias emerja entre la documentación batallando con denuedo contra el energético. A instancias de los jesuitas, que lo habían listado junto al tabaco y el chocolate entre los vicios americanos, el yerno de Garay fue pionero dando bandos contra el consumo y comercio de yerba mate. ${ }^{11} \mathrm{Al}$ autor de Mercado interno no se le escapa sin embargo que, entre los ignacianos, las opiniones estaban divididas $y$, hacia 1630, la explotación de la yerba ya había sido incorporada al universo de actividades económicas de la Orden. Es a partir del declive de la injerencia de Hernandarias en el escenario político rioplatense que Santa Fe comienza a cobrar protagonismo en esta historia.

Las políticas del gobernador que sucedió al yerno de Garay, Francisco de Céspedes, apuradas por las invasiones paulistas, el traslado de Villa Rica -y, en definitiva, el intento de vaciamiento del Guayrá- dan inicio a la salida sostenida de yerba desde Mbaracayú, cuyo "estanco" aumenta prodigiosamente, triplicándose entre 1630 y 1636.

"Una fuente de tipo indirecto [nos dice enseguida] confirma el sostenido aumento de las cantidades exportadas desde Asunción: en efecto, los derechos de romana del puerto de Santa Fe entre 1638 y 1647, hacen ascender a más de 3.300 arrobas anuales -se trata de carga total, es decir incluye todos los productos- a las cantidades que bajan desde el Paraguay." 12

Garavaglia ha hecho visible que, desde antes de su traslado al sitio nuevo, la ciudad ya era el punto de paso de un volumen nada despreciable de mercancías que, si bien no era posible desmenuzar a través del modo en que pudo recuperar la información (los derechos de romana registrados por el cabildo), contenía desde luego la yerba. ${ }^{13}$ Dicha posición pudo haber jugado precisamente un rol fundamental a la hora de elegir el lugar donde trasladar la

10 GARAVAGLIA, Juan Carlos Mercado interno..., cit., pp. 24-25.

11 Cita uno de 1596 contra el consumo y otro de 1607 contra el tráfico, pp. 49 y 50.

12 GARAVAGLIA, Juan Carlos Mercado interno..., cit., pp. 68-69.

13 Algo que no aparece en absoluto de la misma manera en otro gran libro sobre los jesuitas y su economía, cual es el de Magnus Mörner (1924-2012). Es cierto que el libro de Mörner sobre las actividades económicas jesuíticas en el Río de la Plata bajo los Habsburgo se publicó originalmente en 1953 y que el gran historiador sueco no tuvo acceso a muchas de las fuentes que examinó Garavaglia, sin embargo es evidente que lo que hace visible la relación entre el volumen de yerba comercializado y la centralidad santafesina en este tráfico al menos hasta 1720 / 40 no son las fuentes consultadas sino el punto de vista adoptado para examinarlas. 
ciudad, puesto que -entre las razones que los vecinos argumentaban para justificar los apoyos que solicitaban para semejante empresa- la de una mejor ubicación en el circuito que unía a Asunción con Córdoba y Buenos Aires no era la menos importante. ${ }^{14}$

En este libro de Juan Carlos Garavaglia se advierte, desplegado y diseminado a lo largo del texto, aquello que en el artículo de 1973 ("Un modo de producción subsidiario...") alimentaba las notas. Los datos, cualquiera sea su origen -documental o bibliográfico- nunca son convocados sin un propósito preciso, organizado alrededor de una idea, de una composición teórica. Esta provenía de discusiones de aquella hora sobre categorías de análisis, sobre los modos de producción, el concepto de formación económico-social y, en definitiva, sobre las posibilidades que las categorías materialistas ofrecían para interpretar el "hecho colonial", sobre el cual, como se hizo evidente en el debate que mantuvo con Annick Lempérière en 2004, nunca tuvo dudas. ${ }^{15}$

En la presentación al PyP 40, siguiendo una hipótesis que para el Río de la Plata había sido lanzada por Tulio Halperin Donghi en lo que por entonces era su flamante libro, Revolución y Guerra..., escribió: “...el dominio económico del sistema está dado por aquellos que dominan los medios de circulación" ${ }^{16}$ y, unas páginas más adelante, definió el rol del capital comercial en los espacios coloniales como "...el de vehiculizar el excedente generado por los productores directos gracias a distintos modos de producción." [...] ligando formas productivas "...aisladas hasta la víspera entre sí", y despojando a los productores directos e incluso a quienes se apropiaban de su producto -los mineros o los ganaderos, que, afirmaba de la mano del Tomo III de El Capital, caían en las celadas del comerciante. ${ }^{17}$

Esos comerciantes, y esto es central, diferían del capital mercantil en textura y contextura. Para el autor no se trataba de poner nombres a una operación teórica, sino de mostrar cómo estaban incluidos realmente en la teoría hombres de carne y hueso que eran comerciantes de todas las cataduras y giros: grandes, medianos y hasta pequeños mercaderes (sedentarios o movedizos) eran los que movían los hilos del gran tema del libro, la importancia crucial de la formación de un mercado interno en el funcionamiento de una economía colonial.

“El papel del transporte es vital para entender la conformación del mercado interno y, a veces, algunos trabajos de historia colonial dan la impresión que el autor supone que hombres y productos se trasladan por el espacio como por arte de magia... El transporte en esta época significa mulas, bueyes, carretas, barcas; hombres que organizan y lucran, otros que sudan. Montañas y serranías que alejan, ríos que acercan."18

14 Esto había sido subrayado ya por ROVERANO, Andrés Santa Fe la Vieja, Ministerio de Educación y Cultura, Santa Fe, 1960.

15 GARAVAGLIA, Juan Carlos "La cuestión colonial", en Nuevo Mundo Mundos Nuevos [En línea], Debates, Puesto en línea el 08 febrero 2005, URL : http:/ / nuevomundo.revues.org/441 ; DOI : 10.4000 / nuevomundo.441.

16 GARAVAGLIA, Juan Carlos "Introducción", en Modos de producción..., cit., p. 8

17 GARAVAGLIA, Juan Carlos "Introducción", en Modos de producción..., cit., pp. 9 y 10, énfasis en el original.

18 GARAVAGLIA, Juan Carlos Mercado interno..., cit., p. 24. Apenas dos frases permiten ver cómo detestaba (sin hacer nombres) a quienes no podían ver al ser humano en la actividad económica. Apenas dos frases son suficientes para regalar un programa de investigación. 
Hay una media línea en esa frase que lo hace presente en imagen y sonido: “...se trasladan por el espacio como por arte de magia...". No es difícil re-presentárnoslo diciéndola acompañada de un suave movimiento de cabeza y uno más amplio de los brazos, los ojos entornados, tono irónico, el enojo contra la interpretación, contra el pecado sin nombrar al pecador. Esa media línea es, además, la que permite identificar el papel de Santa Fe, sinécdoque para hablar de la ciudad pero sobre todo de sus agentes (comerciantes, jesuitas, cabildo, criadores, fleteros...), en el sistema de la economía colonial.

La progresión es elocuente: desde el Capítulo II del libro la ciudad se vuelve protagonista, para su buenaventura y para su desgracia. En efecto, los datos que ofrecen dos expedientes del Archivo General de Indias, del Archivo Nacional de Asunción y del Archivo General de la Nación (de Sevilla a Asunción y a Buenos Aires, otro itinerario físico) le informan sobre el incremento del registro de ingresos de yerba a Santa Fe, desde Asunción o desde las misiones de los jesuitas, entre 1675 y $1682 .{ }^{19}$ En menos de veinte años el volumen se decuplica. "Y no hay dudas entonces [afirma] que, desde fines de la década del sesenta, el producto local que permite relacionar -limitadamentela región con la economía peruana, será la yerba mate." 20

Despunta el siglo XVIII y de Santa Fe, informan de nuevo papeles separados por un océano, sale mucho menos yerba de la que entra. ${ }^{21}$ ¿Cuáles son los motivos? ¿Las mermas? ¿El consumo de unos habitantes que estima en dos millares para ciudad y campaña? ¿Algo de su utilización como moneda de pago? No lo sabe, pero extrae una advertencia: “...sirve para que no nos dejemos encandilar por las cifras y tomemos a las cantidades que damos en los diversos cuadros, solamente como meros indicadores cuantitativos de la expansión mercantil de la producción..."22

"Durante todo el siglo XVII, Santa Fe era indiscutiblemente el centro más importante de redistribución de la yerba: acudían a la villa mercaderes de todo el Perú en busca de lo que alguien llamó, en 1671, '...el mejor... género que no abundando... ay en todo el Piru para hacer plata...' La ciudad se veía fortalecida todos los años por el constante flujo de recursos que significaba la presencia de los comerciantes y de sus agitados tráficos; toda una serie de actividades menores -arriería, construcción de carretas, alquiler de casas y almacenes, etc.- giraban alrededor de la yerba en esos felices años santafesinos." ${ }^{23}$

El giro comercial registrado por de Santa Fe, documentado en papeles producidos por la ciudad pero conservados en archivos que en ningún caso son

19 Recuerda permanentemente la enorme cantidad de yerba (que podía llegar a duplicar a esta) que las reducciones del Uruguay mandaban directo a Buenos Aires.

20 GARAVAGLIA, Juan Carlos Mercado interno..., cit., p. 71.

21 GARAVAGLIA, Juan Carlos Mercado interno..., cit., Cuadro IV, p. 76.

22 GARAVAGLIA, Juan Carlos Mercado interno..., cit., p. 76. Quizás aquí sí, un ojo más inclinado hacia el Paraguay que hacia Santa Fe. Porque más adelante la reducción del giro santafesino entre 1720 y 1730 es vinculada con las tremendas dificultades que atravesaba la ciudad en su frontera norte: “...la campaña santafesina sufriría, desde la década de 1710-1720, la invasión de malones indígenas que convertirían en pocos años a la ciudad en una sombra de los que había sido. Da inicio en esta época la larga lucha legal de los santafesinos por mantener su condición de puerto preciso." (p. 91) También alude a la situación en la pág. 399 para la década de 1710: “...las grandes invasiones indígenas que harán temblar en poco menos de una veintena de años el dominio santafesino sobre el comercio del Paraguay...".

23 GARAVAGLIA, Juan Carlos Mercado interno..., cit., p. 89-90. 
santafesinos, colocan a la ciudad en un inesperado centro de atención: es el nudo de distribución de un ítem que anuda medio continente. Resulta que Santa Fe es una parte muy importante del espacio peruano; resulta que Santa Fe es también de esta forma, arte y parte de unos circuitos, de una economía, en suma, de una realidad, que es latinoamericana y colonial. Parece innecesario ser más explícito sobre la dimensión americana que está en la base de la constitución de una mirada conectiva sobre los episodios locales.

¿Qué tenían los santafesinos para ofrecer a cambio de la yerba que compensara la mayor parte de ese giro? Ganado.

La larga crisis de producción pecuaria experimentada por el espacio paraguayo a comienzos del siglo XVII, que enseguida se hizo crónica, puso al Paraguay en una relación de franca dependencia en materia de abastecimiento ganadero respecto de Corrientes y Santa Fe. ${ }^{24}$ Las razones, no obstante, escapan a lo económico: originada en los permanentes ataques indígenas sobre las estancias paraguayas, la situación deja como más incidente signo de los tiempos la militarización del campesino. ${ }^{25}$ Como sabemos -y como lo ha señalado Raúl Fradkin en diversos foros últimamente-el Paraguay y los campesinos preocuparon y ocuparon a Juan Carlos hasta sus últimos días, ${ }^{26}$ y esto bien podría encuadrarse dentro de otro de los grandes ejes que atraviesan el libro y que voy a tratar enseguida. Por otra parte, hacia los años 1720 Santa Fe "...donde la aparición de la moneda metálica es una realidad incontrastable...", la ciudad se convierte en el lugar "...donde acuden aquellos que han realizado los cambios en el mercado local en vistas a la acumulación, para procurarse, aun cuando sólo fuera parcialmente, una parte de ese metálico que da sentido a toda la transacción." ${ }^{27}$ En una realidad regional donde el sentido común es hablar de un (matizado) déficit de metálico circulante, Santa Fe era ese punto donde la yerba paraguaya trasmutaba en esa otra medida que daba sentido a la acumulación. Pocos párrafos después lo dice de manera preclara: para el caso de los traficantes asuncenos “...salvo algunos personajes de muy alto vuelo, el punto de encuentro con la economía semimonetaria se dará, hasta fines del siglo XVII, en Santa Fe y posteriormente, en la ciudad de Buenos Aires." 28

Efectivamente, “...el creciente papel económico y militar de Buenos Aires pronto comenzaría a erosionar indefectiblemente el rol de Santa Fe." [...] "Buenos Aires, que en los años 1703/1718 captaba el 20\% del volumen total de salidas desde Santa Fe, en el período 1755/1768 alcanza un 62\% de ese volumen...Por supuesto que este hecho era sólo una de las consecuencias del creciente poderío económico de la ciudad del puerto y sus mercaderes. Éstos habían conseguido que un porcentaje enorme del tráfico yerbatero total, pasara primero por sus almacenes antes de tomar el camino definitivo hacia otros

24 GARAVAGLIA, Juan Carlos Mercado interno..., cit., p. 139.

25 GARAVAGLIA, Juan Carlos Mercado interno..., cit., p. 140.

26 Una síntesis de esta sensibilidad se advierte en su análisis sobre las fuerzas (ahora argentinas, pero compuestas de campesinos que un siglo antes pertenecían a ese espacio paraguayorioplatense) durante la "Guerra Grande". Allí escribió: "La oposición popular a la guerra fue muy extensa en el Interior y en el Litoral. En el Litoral y especialmente, en Entre Ríos, los milicianos entrerrianos -los únicos campesinos soldados del país- veían a la alianza con el Imperio esclavista como una auténtica traición, sobre todo, después de los hechos orientales apañados por los liberales de ambas orillas...". GARAVAGLIA, Juan Carlos "Las fuerzas de guerra argentinas durante el conflicto de la Triple Alianza: 1865-1871", en GARAVAGLIA, Juan Carlos y FRADKIN, Raúl (compiladores) A 150 años de la Guerra de la Triple Alianza contra el Paraguay, Prometeo Libros, Buenos Aires, 2016, p. 116, énfasis en el original.

27 GARAVAGLIA, Juan Carlos Mercado interno..., cit., p. 384.

28 GARAVAGLIA, Juan Carlos Mercado interno..., cit., p. 386. 
centros de consumo. Este pasaje, obviamente, dejaba en las arcas de los comerciantes porteños jugosas ganancias. Es decir que, bastante antes de las (demasiado) célebres medidas de 1778, ya Buenos Aires es el centro económico de mayor poder de atracción de un vasto hinterland." ${ }^{29}$

En las últimas 100 o 120 páginas del libro, la observación sobre el rol de Santa Fe en el esquema explicativo que sostiene la obra es omnipresente. Su rol de articuladora interregional -la expresión textual es muy clara- "...bisagra entre la economía desprovista de metálico del Paraguay y las Corrientes (sic) y la economía monetaria peruana..." 30 clave en la conformación del mercado interno que su libro, a la par de otros, ${ }^{31}$ fueron revelando para abrir una agenda hasta entonces inédita en la historiografía rioplatense. Ese agenda, incluso deslindada de su contexto, alberga todavía decenas de pistas que no han sido continuadas. Actualmente, este libro, que pronto cumplirá 35 años desde su primera edición, podría inscribirse sin ningún tipo de fórceps entre los mejores trabajos de historias conectadas o de global history. ${ }^{32}$

Aquella agenda tiene que ver por supuesto con grandes y pequeños temas históricos e historiográficos, pero sobre todo con un contexto de discusión política sobre el pasado que reverbera con intensidad sin opacar un ápice la profesionalidad desplegada por Juan Carlos Garavaglia en el arte de la investigación -algo que algunos bien no se atreven a reconocer, bien deploran sin advertir su atravesamiento en el propio cuerpo, lo cual les impide distanciarse.

Una de las ventajas que tuvo su producción y la de muchos otros colegas que pusieron sobre el tapete el interés político de la teoría y de la problemática cuyo pasado investigaban (o cuya problemática investigaban en el pasado) radica en que reconocían -y por esto mismo identificaban y explicitaban- a los "copartícipes silenciosos de la teoría". ${ }^{33}$ En los años 1970 y todavía a principios de los 1980 se discutía la teoría de la dependencia, sus funcionalidades en lo político y sus virtudes como instrumento heurístico para el análisis histórico. ${ }^{34}$ Pero discutiendo las interpretaciones de Gunder Frank sobre las relaciones entre

29 GARAVAGLIA, Juan Carlos Mercado interno..., cit., p. 91. Sobre la cuestión del "puerto preciso" y lo que significó la puja con Buenos Aires, quien más ha avanzado es sin dudas Griselda Tarragó. Véase, entre varios de sus trabajos, TARRAGÓ, Griselda "The long kiss of goodbye: Santa Fe and the conflict over the privilege of puerto preciso (1726-1743)", en DE LUCA, Giuseppe \& SABATINI, Gaetano Sabatini -editors-, Growing in the Shadow of an Empire. How Spanish Colonialism Affected Economic Development in Europe and in the World (XVIth-XVIIIth cc.), Franco Angeli Editore, Milano, 2012.

30 GARAVAGLIA, Juan Carlos Mercado interno..., cit., p. 398, énfasis suyo. La incidencia de esta imagen en toda la historiografía colonial santafesina posterior es muy potente y fácil de constatar.

31 Son recurrentes sus citas a los trabajos hasta entonces publicados por Carlos Sempat Assadourian y menos frecuentes pero más agudos, los contrapuntos con las obras de Marcello Carmagnani y su maestro, Ruggiero Romano. El libro de Zacarías Moutoukias, que discute y complementa bien este mismo problema, fue publicado por el Centro Editor de América Latina (Buenos Aires) en 1988.

32 Para ver las características de estas corrientes y los desafíos que hoy enfrentan recomiendo la síntesis de BERTRAND, Romain "Historia global, historias conectadas: ¿un giro historiográfico?", en Prohistoria [online]. 2015, vol. 24, pp. 03-20. Disponible en: http: / / ref.scielo.org/g75rf7

33 POLANYI, Michael Personal Knowledge, Harper \& Row, Nueva York, 1964.

34 El artículo de GELMAN, Jorge "En torno a la Teoría de la Dependencia, los polos de crecimiento y la crisis del siglo XVII. Algunos debates sobre la Historia Colonial Americana", en VVAA Problemas actuales de la Historia, Salamanca, 1993, pp. 99-111, presenta un análisis que, pasados 25 años de su escritura, es todavía un punto de partida extraordinario para visualizar el clima que el mismo Gelman observaba a su vez a unos 25 años de distancia. 
centro y periferia, ${ }^{35}$ las hipótesis que Inmanuel Wallerstein ${ }^{36}$ proponía sobre los orígenes del capitalismo o las tesis de Ángel Palerm sobre la conformación del sistema colonial, ${ }^{37}$ se discutían también los trazos gruesos de problemáticas que son históricas y por eso mismo, nunca abandonan nuestro presente. La historicidad de una problemática no radica en su aparición en la línea del tiempo una vez y para siempre, como un momento que es necesario captar para olvidar. Por el contrario, su presencia en nuestro presente es inevitable y, hundidas en el pasado del espacio paraguayo-rioplatense, están disponibles, esperando la mirada que las rescate: ¿estaban los campesinos adentro o afuera de la gran economía? ¿Podía un mercado interno hacer funcionar una economía subsidiaria a pesar de las crisis de los centros que lo pusieron en marcha, de polos de crecimiento que lo generaron? ¿Funge lo económico como determinación en última instancia o, como parece trasuntar el libro por todas partes, la incidencia de lo político sobre la economía es crucial y toda organización económica no es sino, en última instancia, una manifestación profundamente social?

Juan Carlos viajó como tantas otras veces y no fue una más. Muchos de los que quedamos de este lado del charco sentimos que se nos escurrió. Nos costó y nos cuesta mucho todavía asumir ese proceso que, sin piedad y sobre todo sin pausa, se lo llevó tan pronto. Nos quedan felizmente muchas cosas. Entre otras su obra, generosa, serena, estable, al mismo tiempo madura y fresca pero sobre todo, significante, como dice el epígrafe sobre la obra de Beethoven, sin "fragmentos de relleno". Como su presencia.

Rosario, 18 de mayo / 22 de julio de 2017.

35 Diversos artículos del profesor alemán André Gunder Frank circulaban en América Latina traducidos al español y al portugués desde 1965 y sus trabajos fueron clave como argumentación teórica de las políticas promovidas por la CEPAL, es decir, como justificación del desarrollismo. La trayectoria de Fernando Henrique Cardoso (coautor con Enzo Faletto del clásico de la sociología cepalina latinoamericana Dependencia y desarrollo en América Latina. Ensayo de interpretación sociológica, Siglo XXI, México, 1969) materializó, a la manera de la profecía autocumplida, una de las interpretaciones críticas que se vertían sobre esta clave de análisis.

36 WALLERSTEIN, Immanuel El moderno sistema mundial. I. La agricultura capitalista y los orígenes de la economía-mundo europea en el siglo XVI, Siglo XXI, 4ta. ed., Madrid 1987 -1a.1979- [New York 1974], 579 pp.

37 PALERM, Ángel "Sobre la formación del sistema colonial, apuntes para una discusión”, en FLORESCANO, Enrique (compilador) Ensayos sobre el desarrollo económico de México y América Latina (1500-1975), FCE, México, 1979. 